\title{
Study on the Factors Affecting the Determination of Calcium in Limestone for Chemical Industry by AAS
}

\author{
Wen $\mathrm{He}^{1}$, Chengfeng Dang ${ }^{1}$ and Xing Gao ${ }^{1 *}$ \\ ${ }^{1}$ School of Chemistry and Bioengineering, Qilu Institute of Technology, Jinan, Shandong, 250200, China
}

\begin{abstract}
The calcium content in limestone for chemical industry was determined by atomic absorption spectrometry. The effects of soaking time, soaking reagent and soaking temperature on the determination of calcium content in limestone for chemical industry were discussed by the method of controlling variables, and the optimum conditions for the determination of calcium content in limestone for chemical industry were analyzed. This method has the advantages of easy operation, low interference, high accuracy and sensitivity, and is widely used. The experimental results show that the optimum conditions for the determination of calcium content in limestone for chemical industry are as follows: soaking reagent is $0.6 \mathrm{~mol} / \mathrm{L}$ hydrochloric acid, soaking time is $0.5 \mathrm{~h}$, soaking temperature is $70 \sim 80{ }^{\circ} \mathrm{C}$.
\end{abstract}

\section{Introduction}

Calcium hydroxide is commonly known as slaked lime. It is a material based on limestone and is the "first filler" in the industry[1]. It is a kind of binary medium strong alkali with the generality of alkali, which has corrosive effect on skin and fabrics. Calcium hydroxide is processed into high-quality ash as raw material through strict calcination, and then processed by careful selection[2]. The application field of calcium hydroxide is becoming more and more extensive. It is a commonly used building material, also used as a fungicide and chemical raw material, and its industrial development is also very rapid. Calcium hydroxide has the following uses in the chemical industry: (1) The application of calcium hydroxide in the coating industry is also very extensive. In addition to being used as fillers in coatings, it also replaces titanium dioxide and pigments, and is also used to replace light calcium and precipitated barium sulfate[3]; (2) In the rubber industry, calcium hydroxide is used as a filler for rubber products, which can improve the processing performance of rubber and improve the mechanical properties of products, such as increasing the tear or tear strength, flex resistance, and achieve initial strength or semi-reinforced effect[4]; (3) The important inorganic filler in the paper industry is still calcium hydroxide, which can improve the penetration and diffusion of paper products[5]. Therefore, it is of great significance to study how to accurately determine the content of calcium in limestone for chemical industry.

There are many methods for the determination of calcium in limestone for chemical industry, such as mass spectrometry, atomic absorption spectrometry (AAS) and chemical titration[6-7]. The operation process of chemical titration is very tedious, and the analysis time is long, the analysis and determination of trace calcium is even more difficult, there are many interference factors, the titration end point is not obvious, and the personal operation error and subjective error are also relatively large. For the determination of trace elements in limestone for chemical industry, it is usually necessary to pretreat the sample, either wet digestion with concentrated hydrochloric acid and concentrated nitric acid, or ashing at $550{ }^{\circ} \mathrm{C}$ to remove organic matter, and then determine it by spectrophotometry or atomic absorption spectrometry.

In this experiment, dry ashing method was used to treat limestone for chemical industry, and then all kinds of limestone for chemical industry samples were prepared, and then determined by air-acetylene flame AAS. A scheme for the determination of calcium content in limestone for chemical industry was obtained by controlling a variable to explore the factors that affect the determination of calcium content, such as soaking time of limestone for chemical industry, type and concentration of soaking reagent and soaking temperature.

\section{Experimental method}

\subsection{Preparation of calcium standard solution}

Accurately weigh $0.0645 \mathrm{~g} \mathrm{CaCO}_{3}$ in small $50 \mathrm{~mL}$ beaker, add a small amount of distilled water to dissolve, add $2.0 \mathrm{~mL} \mathrm{HCl}$ and stir until $\mathrm{CaCO}_{3}$ is completely dissolved, use distilled water to fix volume in $250 \mathrm{~mL}$ capacity flask, shake well and set aside. The above solutions of $0.00,1.00,2.00,3.00,4.00$ and $5.00 \mathrm{~mL}$ were diluted to scale with water in $650 \mathrm{~mL}$ volumetric flasks, and the calcium standard solutions with concentrations of $0.0000,0.0020$, $0.0040,0.0060,0.0080$ and $0.0100 \mathrm{mg} / \mathrm{mL}$ were prepared. According to the order of concentration from low to high, 
the absorbance was determined by air-acetylene flame AAS.

\subsection{Pretreatment of limestone for chemical industry}

$4.8000 \mathrm{~g}$ limestone for chemical industry was accurately weighed in a porcelain crucible with an electronic balance and burned with an alcohol lamp until the limestone for chemical industry was carbonized and turned gray. Remove the porcelain crucible and put it into a box-type resistance furnace whose temperature is adjusted to $500{ }^{\circ} \mathrm{C}$, continue ashing for 1.5 hours, cool and take out, put it into the dryer and set aside.

\subsection{Preparation of samples}

(1) Limestone for chemical industry samples soaked in different kinds of acid

$0.2021 \mathrm{~g}, 0.2020 \mathrm{~g}, 0.2021 \mathrm{~g}$ and $0.2022 \mathrm{~g}$ limestone for chemical industry were accurately weighed in the crucible. After the limestone for chemical industry was pretreated, they were transferred to four $50 \mathrm{~mL}$ beakers, then $5 \mathrm{~mL}$ $\mathrm{HCl}, 12 \mathrm{~mL} \mathrm{HNO} 3,8 \mathrm{~mL} \mathrm{H} 3 \mathrm{PO} 4$ and $7 \mathrm{~mL} \mathrm{HClO} 4$ were added to completely dissolve them, and then shaken well in four $100 \mathrm{~mL}$ capacity bottles. Finally, the solutions of $7.80 \mathrm{~mL}, 1.80 \mathrm{~mL}, 2.50 \mathrm{~mL}$ and $2.90 \mathrm{~mL}$ were taken from the 4 volumetric flasks and fixed volume into $450 \mathrm{~mL}$ volumetric flasks. Shake well and set aside. Repeat the above operation 3 times. The absorbance was determined by air-acetylene flame atomic absorption spectrometry. Take appropriate amount of $\mathrm{HCl}, \mathrm{HNO} 3, \mathrm{H} 3 \mathrm{PO} 4$ and $\mathrm{HClO} 4$ solution in $50 \mathrm{~mL}$ volumetric flask, shake well with distilled water, and prepare the blank solution of each acid.

(2) Limestone for chemical industry samples soaked in different concentrations of hydrochloric acid

The limestone for chemical industry of $0.2023 \mathrm{~g}$, $0.2022 \mathrm{~g}, \quad 0.2021 \mathrm{~g}, 0.2021 \mathrm{~g}, 0.2023 \mathrm{~g}, 0.2023 \mathrm{~g}$ and $0.2022 \mathrm{~g}$ were accurately weighed in the crucible. After the limestone for chemical industry was pretreated, it was dissolved in hydrochloric acid with the concentration of $0.2 \mathrm{~mol} / \mathrm{L}, 0.4 \mathrm{~mol} / \mathrm{L}, 0.6 \mathrm{~mol} / \mathrm{L}, 0.8 \mathrm{~mol} / \mathrm{L}, 1.0 \mathrm{~mol} / \mathrm{L}, 1.2$ $\mathrm{mol} / \mathrm{L}$ respectively, and then diluted and fixed volume into $100 \mathrm{~mL}$ capacity bottles, shake well and set aside. The absorbance was determined successively by air-acetylene flame AAS.

(3) Limestone for chemical industry samples with different soaking time
$0.2021 \mathrm{~g}, 0.2020 \mathrm{~g}, 0.2021 \mathrm{~g}, 0.2022 \mathrm{~g}, 0.2020 \mathrm{~g}$ and $0.2021 \mathrm{~g}$ limestone for chemical industry were accurately weighed in the crucible. After the limestone for chemical industry was pretreated, $5 \mathrm{~mL}$ water and $6 \mathrm{~mL} \mathrm{HCl}$ were added into the $50 \mathrm{~mL}$ beaker until completely dissolved. When the six samples were soaked in $0.5 \mathrm{~h}, 1 \mathrm{~h}, 2 \mathrm{~h}, 3 \mathrm{~h}, 4 \mathrm{~h}$ and $5 \mathrm{~h}$ respectively, the $0.60 \mathrm{~mL}$ solution was absorbed by $1 \mathrm{~mL}$ pipette and shaken well in $50 \mathrm{~mL}$ volumetric bottles, and the absorbance was determined by air-acetylene flame AAS.

(4) Limestone for chemical industry samples soaked at different temperatures

$0.2023 \mathrm{~g}, \quad 0.2021 \mathrm{~g}, \quad 0.2021 \mathrm{~g}, \quad 0.2023 \mathrm{~g}, \quad 0.2020 \mathrm{~g}$, $0.2022 \mathrm{~g}, 0.2020 \mathrm{~g}$ and $0.2022 \mathrm{~g}$ limestone for chemical industry were accurately weighed in the crucible. After the pretreatment of limestone for chemical industry, the limestone for chemical industry was dissolved in $50 \mathrm{~mL}$ beaker with water of $30^{\circ} \mathrm{C}, 40{ }^{\circ} \mathrm{C}, 50{ }^{\circ} \mathrm{C}, 60^{\circ} \mathrm{C}, 70^{\circ} \mathrm{C}$, $80{ }^{\circ} \mathrm{C}, 90{ }^{\circ} \mathrm{C}$ and $100{ }^{\circ} \mathrm{C}$ respectively, then $6 \mathrm{mLHCl}$ was added and stirred until completely dissolved, and then the water at the above temperature was used to fix the volume into the $100 \mathrm{~mL}$ capacity bottle. After all the samples were cooled to room temperature, the $6.5 \mathrm{~mL}$ test solution was removed from capacity bottles and shaken well in the $50 \mathrm{~mL}$ capacity bottle. Sequential determination of absorbance by air-acetylene flame AAS.

\section{Results and discussion}

\subsection{Drawing of calcium standard curve}

The set wavelength is $422.7 \mathrm{~nm}$, the slit width is $0.7 \mathrm{~nm}$, the lighting mode is BGD-D2, lamp current $10 \mathrm{~mA}$, the gas type is air-acetylene, the absorbance of a series of calcium standard solutions in the $0 \sim 0.0100 \mathrm{mg} / \mathrm{mL}$ range is determined, and the calcium standard curve is drawn as shown in Figure 1.

It can be seen from figure 1 that the regression equation of the standard curve is $y=41.5557 x-0.00804$ ( $x$ represents the concentration of the standard solution and $\mathrm{y}$ represents absorbance), and the correlation coefficient is $0.9993(n=6)$. The standard curve is linear in the range of $0 \sim 0.0100 \mathrm{mg} / \mathrm{mL}$. From the trend of the standard curve of calcium, it can be seen that when the absorbance increases, the concentration of calcium increases. As a result, it can be concluded that the higher the absorbance of the sample measured in the following experiments, the higher the concentration of calcium, on the contrary, the measured concentration of calcium is also small. 


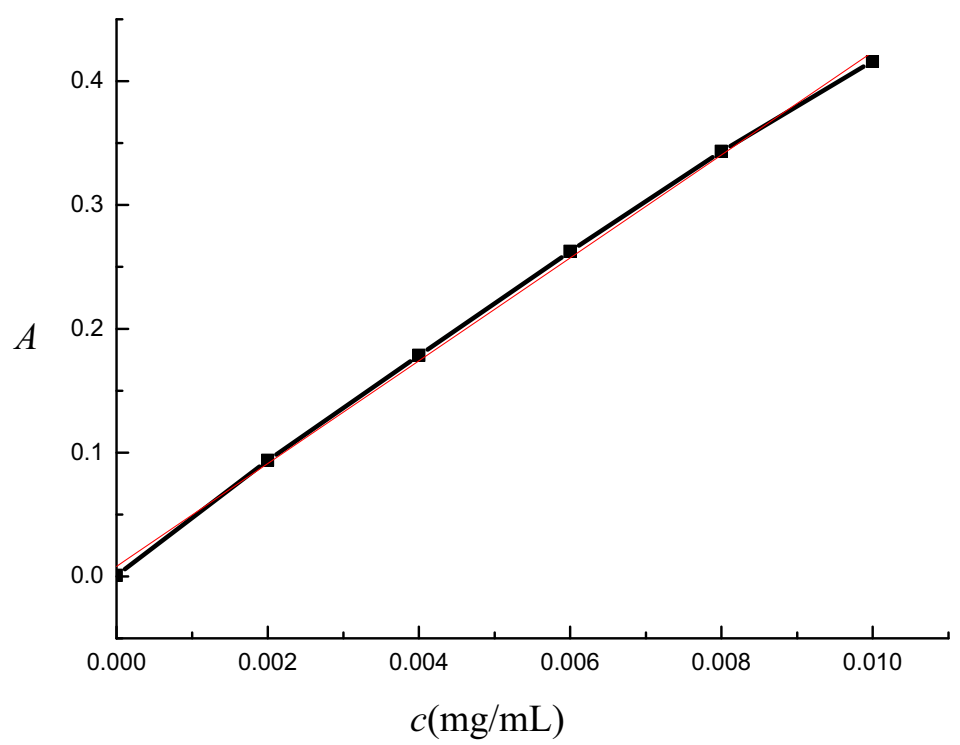

Figure 1. Calcium standard curve.

\subsection{Single factor experiment}

The effects of acid type, hydrochloric acid concentration, soaking time and soaking temperature on calcium in limestone for chemical industry were studied by AAS. The content of calcium in limestone for chemical industry was reflected by absorbance through the standard curve of calcium.

\section{(1) Types of acids}

The samples of limestone for chemical industry dissolved with hydrochloric acid, nitric acid, phosphoric acid and perchloric acid were prepared respectively. The operation was repeated for 3 times, and parallel experiments were carried out. Finally, the average value of the data measured in the three experiments was obtained, and the curve was drawn as shown in Figure 2.

It can be seen from Figure 2 that among the four acids, the calcium absorbance of limestone for chemical industry dissolved in hydrochloric acid is the highest, which is 0.2369 , followed by phosphoric acid (0.1406). The absorbance of calcium measured by dissolving limestone for chemical industry with nitric acid and perchloric acid is very low, which is 0.0907 and 0.0526 respectively. According to the standard curve of calcium, the concentration of calcium increases with the increase of absorbance. Therefore, it is concluded that the calcium concentration of limestone for chemical industry dissolved with hydrochloric acid is the highest, and this extractant is the best.

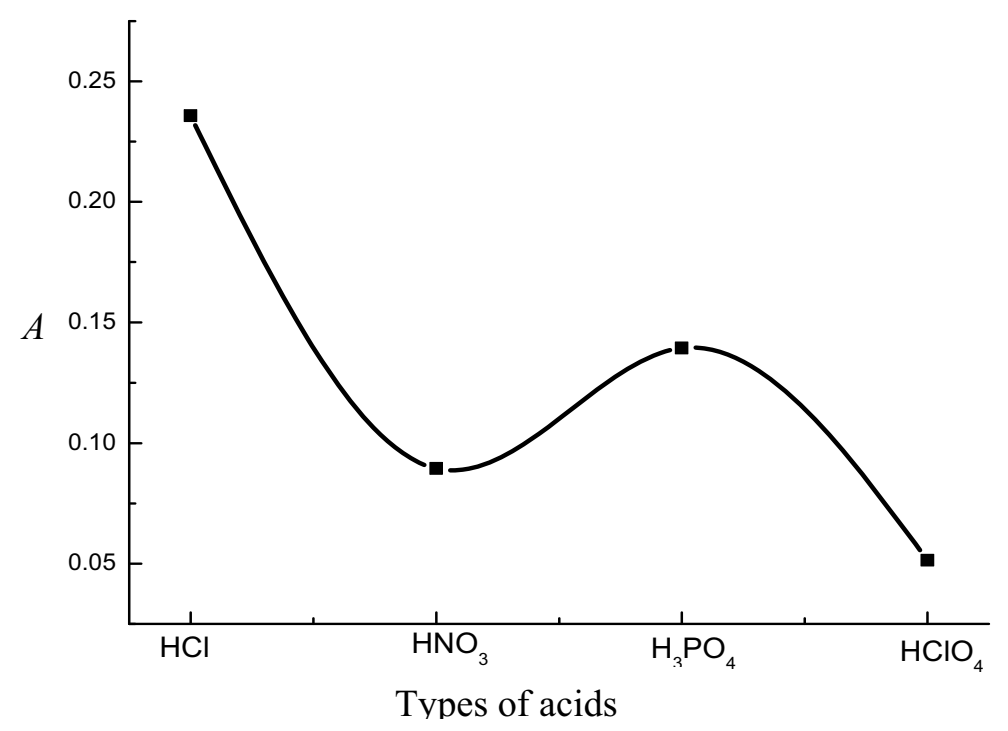

Figure 2. Effect of kinds of acids on the determination of calcium. 
(2) Hydrochloric acid concentration

The effect of hydrochloric acid concentration on the determination of calcium, and the relationship between its concentration and absorbance is shown in Figure 3. It can be seen from the data trend of Figure 3 that the absorbance of calcium increases rapidly when the concentration of hydrochloric acid is $0.2 \sim 0.4 \mathrm{~mol} / \mathrm{L}$. With the increase of the concentration, the absorbance of calcium reaches the maximum value of 0.2401 , and the concentration is $0.6 \mathrm{~mol} / \mathrm{L}$. After that, with the further increase of the concentration, the absorbance of calcium decreased slowly. In this experiment, the lowest absorbance of calcium was 0.1505 when the concentration of hydrochloric acid was $1.2 \mathrm{~mol} / \mathrm{L}$. To sum up, when the concentration of hydrochloric acid is $0.6 \mathrm{~mol} / \mathrm{L}$, the calcium concentration of dissolved limestone for chemical industry is the highest, which is the best concentration.

(3) Soaking time

The effect of soaking time of limestone for chemical industry on calcium content, and the relationship between soaking time and absorbance is shown in Figure 4. It can be seen from the data trend of Figure 4 that the absorbance of calcium decreases gradually with the extension of soaking time of limestone for chemical industry. When the soaking time is $0.5: 1 \mathrm{~h}$, the absorbance of calcium is higher, and the highest absorbance is 0.2291 . When the soaking time is more than 3 hours, the absorbance of calcium is lower. It is inferred that when the soaking time is $0.5 \mathrm{~h}$, its absorbance is the highest, and the calcium concentration is also the highest. It shows that the sample should be determined in time, and the longer the soaking time is, the greater the influence is.

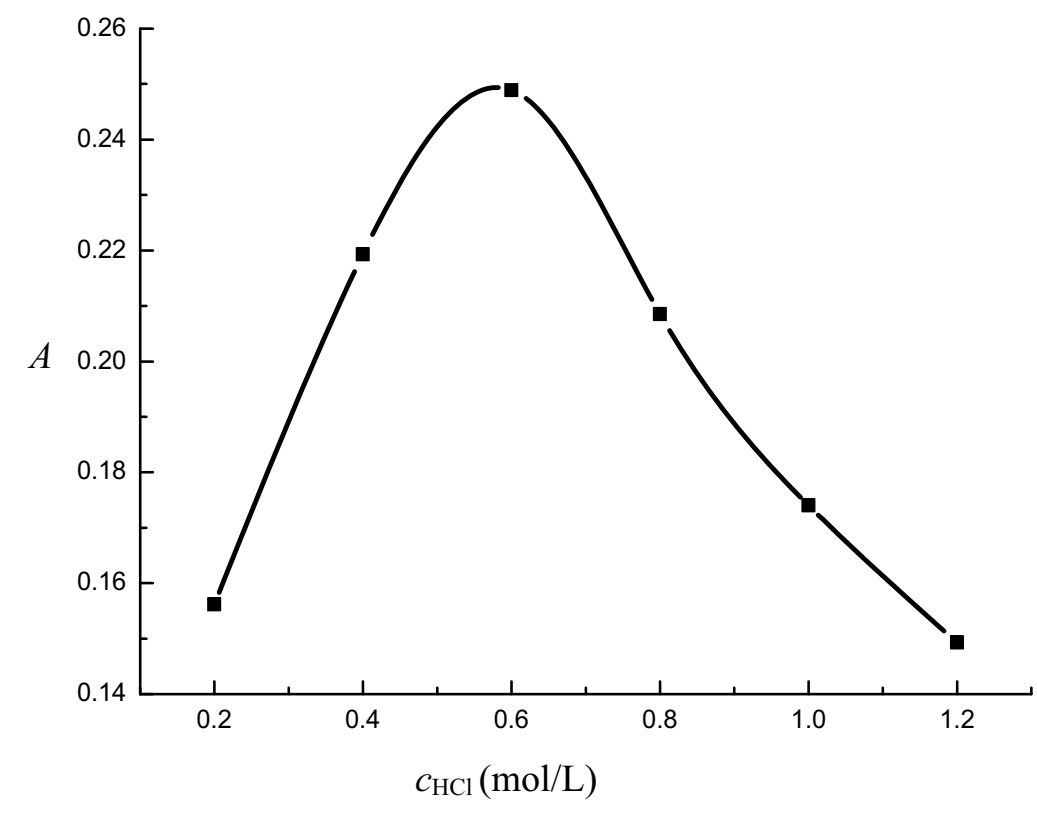

Figure 3. Effect of hydrochloric acid concentration on the determination of calcium. 


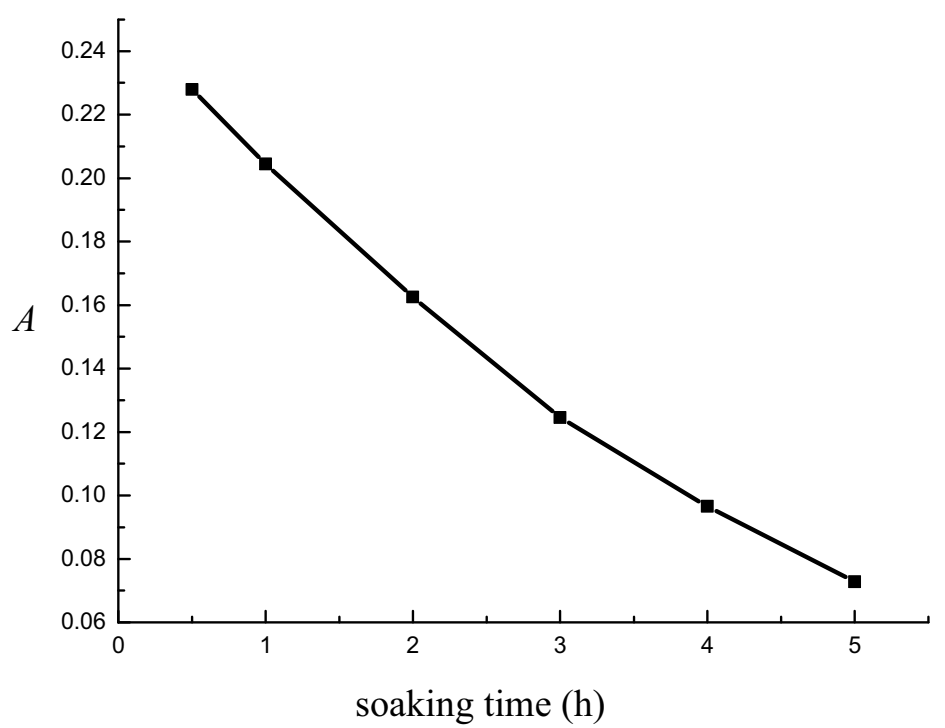

Figure 4. Effect of soaking time on the determination of calcium.

(4) Soaking temperature

The effect of various soaking temperatures on the determination of calcium, and the relationship between soaking temperature and absorbance is shown in Figure 5. As can be seen from the data trend of Figure 5, with the increase of soaking temperature of limestone for chemical industry, the absorbance of calcium increased at first and then decreased by $10 \%$. When the temperature is about 30 $\sim 70^{\circ} \mathrm{C}$, the absorbance of calcium increases continuously, and when the temperature reaches $70 \sim 80{ }^{\circ} \mathrm{C}$, the absorbance of calcium reaches the maximum value of 0.2488 , so the concentration of calcium is the highest. Then, with the continuous increase of temperature, the absorbance of calcium decreased at $80-100{ }^{\circ} \mathrm{C}$. Therefore, in daily life, brewing limestone for chemical industry generally does not need warm water with too low temperature, nor boiling water with too high temperature.

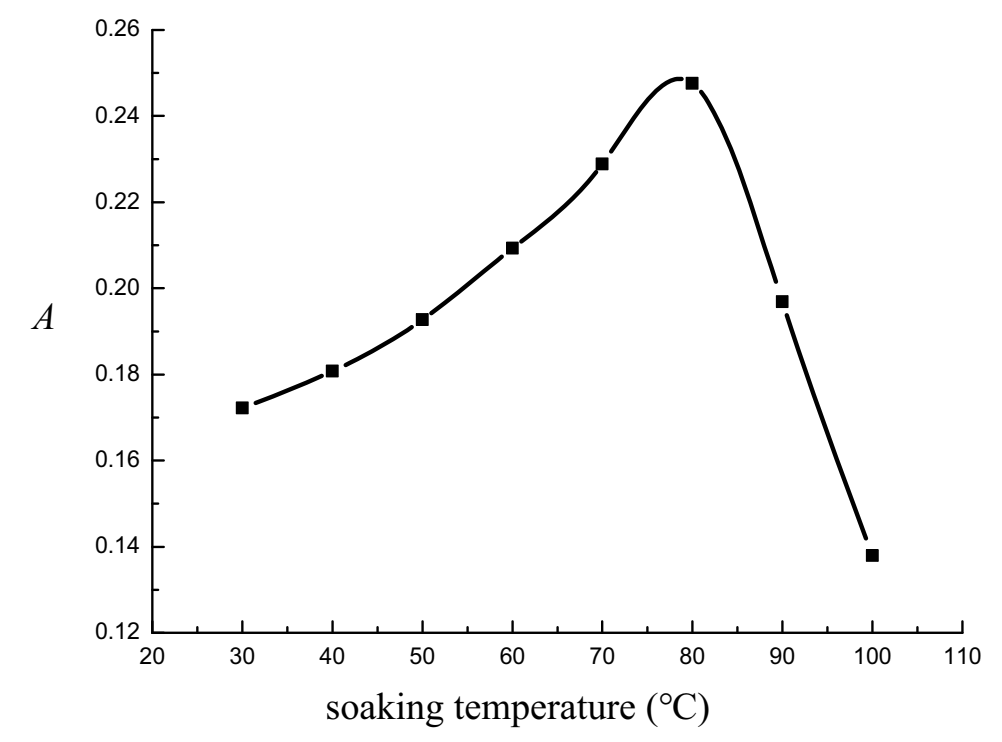

Figure 5. Effect of soaking temperature on the determination of calcium.

\section{Conclusion}

From the experimental data, the optimum conditions for the determination of calcium content in limestone for chemical industry by AAS are as follows: soaking reagent is $0.6 \mathrm{~mol} / \mathrm{L}$ hydrochloric acid, soaking time is $0.5 \mathrm{~h}$, soaking temperature is $70 \sim 80{ }^{\circ} \mathrm{C}$. The calcium content in limestone for chemical industry is $48 \sim 55.22 \% \%$.

\section{References}

1. Dinnin J I. Releasing effects in flame photometry. 
determination of calcium[J]. Anal. Chem. 1960, 32(11): $1475-1480$

2. Wellington D S L, Luciano F D A, Francisco Antônio D S C, et al. Determination of sodium and calcium in powder milk using digital image-based flame emission spectrometry[J]. Anal. Methods, 2014,6, 1044-1050

3. Masotti F, Cattaneo S, Stuknyte M, et al. Analytical advances in the determination of calcium in bovine milk, dairy products and milk-based infant formulas[J]. Trends in Food Science \& Technology, 2020, 103, 348-360

4. Andrew T, Martin P D, Sarah H, et al. Atomic spectrometry update: review of advances in the analysis of clinical and biological materials, foods and beverages[J]. J. Anal. At. Spectrom., 2015, 30, 542-579

5. Laurent N, Michael C, Christelle V, et al. Determination of sodium, potassium, calcium and magnesium content in milk products by flame atomic absorption spectrometry (FAAS): A joint ISO/IDF collaborative study[J]. International Dairy Journal, 2008, 9(18): 899-904

6. Khammas Z A, Marshall J, Littlejohn D, et al. Determination of copper in limestone for chemical industry by electrothermal atomic absorption and atomic emission spectrometry[J]. Mikrochim Acta 85, 1985, 333-355

7. Khalid N, Rahman S, Ahmed R, et al. Determination of Lead and Cadmium in Milk by Electrothermal Atomic Absorption Spectophotometry[J]. International Journal of Environmental Analytical Chemistry, 1987, 28(1-2): 133-141 